\title{
THE EFFECT OF IRRIGATION ON LIGHT LAND DEVELOPMENT IN MID CANTERBURY \\ B. M. Evans
}

(M.A., University of Canterbury)

This, thesis reviews the development over the past 30 years of an area of light land in Mid Canterbury, New Zealand. The aim is to examine the effect that irrigation has had on this development.

Development is defined in terms of increased production, greater flexibility, or more intensive land use. Both archival research and a survey of a $30 \%$ random sample of farmers is used to gather base data from an irrigated and adjacent dryland zone. These zones have similar cultural and physical characteristics.

From the pre-irrigation base levels of 1938, development in both the irrigated and dryland zones with respect to production has been similar. As the objectives of the irrigation scheme were to increase both productivity and rural population, it has not fulfilled its purpose.

Attempts were made to measure social situational and psychological factors which might account for the small differences between the irrigated and dryland zones and the wide variations between farms. None of the factors examined could account for these differences unless a motivational factor was postulated. It was found impossible to measure such a factor with the data obtained, and more research into this aspect is needed.

The conclusion reached was that while irrigation could be effective in increasing production, lack of knowledge, lack of planning, and a perceptual gap between authorities and farmers resulted in the failure of this particular scheme to reach its objectives. 